\title{
O ensaio pós-literário
}

Raul Antelo

UFSC

\begin{abstract}
Resumo
Este trabalho explora os sentidos do ensaístico em relação com os problemas contemporâneos da voz, do denominado "fim da história", do saber arqueológico e, portanto, da soberania. Também evidencia o atrelamento inevitável de toda sigética (o abismo como fundamento) à metafísica (o absoluto como fundamento) para, por um deslizamento entre sage e saggistica, mostrar a maneira em que é na sabedoria do ensaio onde satisfação e insatisfação se tornam, enfim, sensíveis. Através de uma arqueologia do saber ensaístico, particularmente na sua fase moderna, o trabalho evidencia a maneira em que esse saber se situa na indecidibilidade -entre signo e discurso, entre completude e fragmento, ou entre o semiótico e o semântico; entre a realização e a tentativa, ou entre afirmação e negação, ou entre a identidade e a sua procura, ou entre ser e não ser-, fazendo com que o seu acontecimento seja uma forma singular de cura sui, um extremo de potência para além do mero fato literário cronologicamente ordenado e hierarquizado. Finalmente, se pensam os avatares de um ensaio latino-americano que encontra a possibilidade de escrever uma experiência íntima sem limites, a sutil comunidade dos que carecem de algo em comum.
\end{abstract}

Palavras-chave: ensaio; literatura latino-americana; soberania; comunidade; potência.

\section{Resumen}

Este trabajo explora los sentidos de lo ensayístico en relación con los problemas contemporáneos de la voz, del denominado "fin de la historia", del saber arqueológico y, por tanto, de la soberanía. También evidencia la articulación inevitable de toda sigética (el abismo como fundamento) a la metafísica (el absoluto como fundamento) para, por un deslizamiento entre sage y saggistica, mostrar cómo es en la sabiduría del ensayo donde satisfacción e insatisfacción se tornan, finalmente, sensibles. A través de una arqueología del saber ensayístico, particularmente en su fase moderna, el trabajo evidencia el modo en que ese saber se sitúa en la indecidibilidad -entre signo y discurso, entre completud y fragmento, o entre lo semiótico y lo semántico; entre la realización y la tentativa, o entre afirmación y negación, o entre la identidad y su búsqueda, o entre ser y no ser-, haciendo que su acontecimiento sea una forma singular de cura sui, un extremo de potencia más allá del mero hecho literario cronológicamente ordenado y jerarquizado. 
Finalmente, se piensan los avatares de un ensayo latinoamericano que encuentra la posibilidad de escribir una experiencia íntima sin límites, la sutil comunidad de los que carecen de algo en común.

Palabras clave: ensayo; literatura latinoamericana; soberanía; comunidad; potencia.

\section{Riassunto}

Questo studio esplora i sensi della saggistica rispetto ai problemi contempora-nei della voce, del cosiddetto "fine della storia", del sapere archeologico, dunque, della sovranità. Pone in evidenza anche l'inevitabile relazione di ogni siggetica (la voragine come fondamento) con la metafisica (l'assoluto come fondamento) per mostrare, attraverso uno spiegamento tra sage e saggistisca, la maniera in cui è nella saggezza di ogni saggistica che soddisfazione e insoddisfazione divengono infine sensibili. Così, mentre presenta un ricorso archeologico del sapere saggistico, specialmente nella sua fase moderna, lo studio pone in evidenza la maniera in cui questo stesso sapere si colloca nella frangia dell'indecibilità - tra segno e discorso, tra compiutezza e frammentarietà, tra l'evento semiotico e quello semantico, tra la realizzazione e il suo tentativo, tra l'affermazione e la negazione, tra l'identità e la sua ricerca, o ancora tra l'essere e il non essere. In questo senso, lo studio fa che il suo avvenimento sia una forma singolare della cura sui, uno spazio estremo di potenza al di là dal mero fatto letterario cronologicamente ordinato e gerarchizzato. Finalmente, vengono pensati gli avatar di una saggistica latinoamericana che trova la possibilità di scrivere una sperienza intima sensa limiti, ossia l'ingegnosa comunità di coloro a chi manca qualcosa in comune.

Parole chiave: Saggistica; Letteratura latinoamericana; Sovranità; Comunità; Potenza. 
The essay as a literary form has a natural affinity to the exercises I have in mind.

Hannah Arendt - prefácio a Between Past and Future

\section{Ensaio e sabedoria}

No quarto excurso, entre a quinta e a sexta jornada de $A$ linguagem e a morte, Giorgio Agamben cita uma correspondência, conforme nos diz, inédita, de Kojève a Bataille. Nela discute-se a tese do filósofo russo acerca do fim da história, associada a questões tais como a animalidade, sua relação com o evento heideggeriano e, last but not least, a inoperosidade, questões todas, como sabemos, que preocupavam Bataille desde a época, 1922, em que viu, no museu de Cluny, e na própria Espanha, as espadas de Boabdil, o rei árabe expulso de Granada pelos Reis Católicos ${ }^{1}$. Reivindica-se assim o desejo e o gozo do Amo, na figura do Morto (das Tote).

À pretensão de quem desejasse reivindicar o gozo do senhor, Hegel teria de fato respondido precisamente com o mistério eleusino que, no início da Fenomenologia, opõe à Meinung da certeza sensível: certamente a consciência sensível é o fundamento do qual parte a dialética, mas a sua verdade é a de ser um puro nada, e como tal inapreensível e indizível, e é, pois, como um nada e como um negativo que a pietas $\mathrm{da}$ Wahrnehmung a recolhe da única maneira possível: proferindo-a em palavras. Do mesmo modo, o gozo do senhor parece ter-se liberado, no seu imediato evanescer, da dialética: mas ele se liberou dela apenas como um nada, um evanescente, que não pode ser de modo algum dito ou apreendido (neste sentido, ele é "sem emprego"); o único modo de dizê-lo e captá-lo é aquele do servo que o conserva, como nada, no seu trabalho.

O problema é, aqui, poderíamos dizer, o da "voz" do senhor: se, de fato, o senhor consegue verdadeiramente gozar e subtrair-se ao movimento da dialética, ele deve ter, no seu prazer, uma voz animal (ou, antes, divina): precisamente aquilo que o homem jamais consegue fazer, permanecendo preso no discurso significante. (O que significa que o gozo do senhor não é uma figura do humano, mas do animal, ou melhor, do divino, e que diante dele se pode somente calar ou, no limite, rir. $)^{2}$

Esse problema da satisfação está no cerne da tal carta que Agamben atribui a Kojève, mas que Edgardo Castro já esclareceu que pertence a Bataille ${ }^{3}$. Agamben confunde as vozes e
1. BATAILLE, Georges.

L'apprenti sorcier. Textes, lettres

et documents (1932-9), 1999;

BAILEY GILL, Carolyn.

Bataille: writing the sacred, 1995;

GRASSI, Carlo. Il non-sapere.

Georges Bataille, sociologo della

conoscenza, 1998.

2. AGAMBEN, Giorgio. $A$

linguagem e a morte: um seminário sobre o lugar da negatividade, 2006, p. $71-72$.

3. CASTRO, Edgardo. Giorgio Agamben: una arqueologia de la potencia, 2008, p. 145. 
4. Relembremos a conclusão, inconclusiva, com que, em 1980, se encerra "Vocação e voz", um dos ensaios de $A$ potência do pensamento: "Ma può la Stimmung, diventando Stimme, dare al linguaggio un luogo e, in tal modo, appropriarlo all'uomo, all'animale senza voce? Può l' appassionata vocazione storica che l'uomo riceve dal linguaggio trasformarsi in voce? Può la storia diventare natura dell' uomo:? O non si limita essa piuttosto a portare l' uomo di fronte alla sua assenza di voce, alla sua afonia, mettendolo, con ciò, puramente e immediatamente di fronte al linguaggio?". AGAMBEN, Giorgio. La potenza del pensiero. Saggi e conferenze, 2001, p. 89-90.

5. É o que se lê, em julho de 1938, na Nouvelle Revue Française, quando Caillois, Bataille e

Leiris apresentam o Colégio de Sociologia. Caillois republicaria o seu texto, "Vento do inverno", um ano depois, na revista argentina Sur e o incorporaria a seu volume Aproximações ao imaginário. Sobre o particular, Cf. FAYE, Jean-Pierre. "Feu et froid: le Collège de Sociologie autour de Georges Bataille”, 1987, p. 95-101. toma a adynamia de um como dynamis do outro ${ }^{4}$. Assim sendo, é a voz de Bataille a que adverte Kojève:

le terrain où vous vous engagez est glissant: il me semble malgré tout qu'à ne vous y engager qu'à demi, à ne pas avouer que cette satisfaction dont vous parlez n'est pas saisissable, étant en somme et du moins au sens le plus parfait une farce, vous manquez à la politesse élémentaire... Il faudrait à la vérité pour être complet trouver un ton indéfinissable qui ne soit ni celui de la farce ni celui du contraire et il est évident que les mots ne sortent qu'à une condition du gosier: d'être sans importance. Je crois toujours que vous minimisez l'intérêt des expressions évasives que vous employez au moment où vous débouchez dans la fin de l'histoire. C'est pourquoi votre article me plaît tant, qui est la façon d'en parler la plus dérisoire - c'est-àdire, la moins evasive.

Um meio tom, entre a farsa e a tragédia, algo que, ao mesmo tempo, é e não é. De modo que é, portanto, Bataille, ainda, quem critica Kojève nos seguintes termos:

Seulement vous allez peut-être vite, ne vous embarrassant nullement d'aboutir à une sagesse ridicule: il faudrait en effet représenter ce qui fait coincider la sagesse et l'objet $\mathrm{du}$ rire. Or je ne crois pas que vous puissiez personellement éviter ce problème dernier. Je ne vous ai jamais rien entendu dire en effet, qui ne soit expressément et volontairement comique au moment d'arriver à ce point de resolution. C'est peut-être la raison pour laquelle vous avez parfois accepté de faire une part à ma propre sagesse.

Malgré tout, ceci nous oppose: vous parlez de satisfaction, vous voulez bien qu'il y ait de quoi rire, mais non que ce soit le principe même de la satisfaction qui soit risible.

Nesse sentido, a controvérsia de Bataille com Kojève é a mesma que opunha Bataille a Caillois (quem queria substituir Amo e Escravo por Produtores e Consumidores ${ }^{5}$ ), e reside, basicamente, na questão da soberania, isto é, no modo mais correto de colocar o sábio (saggio) no fim da história, de tal sorte que, nesse ponto, satisfação e insatisfação se equivaleriam ("l'identité de la satisfaction et de l'insatisfaction devient sensible"). Ora, o mesmo Agamben relembra uma outra carta, de Kojève a Bataille (28 jul. 1942), em que Kojève discute mística e silêncio e conclui com uma exortação a retornar à perspectiva da sabedoria (saggezza) hegeliana: "Je vous souhaite donc de la puissance à l'acte, de la philosophie à la sagesse. Mais pour cela réduisez à néant ce qui n'est que néant, c'est-à-dire réduisez au silence la partie angélique de votre livre." 
Dessa leitura, finalmente, Agamben conclui:

Um pensamento que queira pensar para além do hegelianismo não pode, efetivamente, encontrar fundamento, contra a negatividade dialética e o seu discurso, na experiência (mística e, se coerente, necessariamente muda) da negatividade sem emprego; ela deve, em vez disso, encontrar uma experiência da palavra que não suponha mais nenhum fundamento negativo. Nós vivemos hoje naquela extrema fímbria da metafísica em que esta retorna - como niilismo - ao próprio fundamento negativo (ao próprio $A b$-grund, à própria não-fundamentação). Se o abismarse do fundamento não revela, porém, o êthos, a morada habitual do homem, mas limita-se a mostrar o abismo de Sigé, a metafísica não é superada, mas reina na sua forma mais absoluta - ainda que esta forma (como sugere Kojève e como confirmam alguns aspectos da gnose antiga e daquela de Bataille) seja, eventualmente a de uma "farsa".

Caberia, entretanto, não apenas repor, como fizemos, a autêntica autoria das ponderações sobre o lugar do saggio no fim da história, mas ainda jogar com a própria duplicidade de sentidos em que podemos ler a palavra utilizada por Agamben (saggio) que, embora traduza o sage de Bataille, é um termo que, em italiano, também significa ensaio, donde poderíamos concluir que é na sabedoria do ensaio onde satisfação e insatisfação se tornam, finalmente, sensíveis. Numa outra carta, derradeira (2 jun. 1961), ao mesmo Kojève, depois de elogiar a Introdução à leitura de Hegel, Bataille admite que gostaria de tratar aquilo que Hegel não quis ver (a pré-história, o presente, o porvir) e assim colocar "à la base même (ou à la fin) de la réflexion hégelienne une équivalence de la folie"7. Mas essa já é a tarefa de Foucault, autor de "A loucura, a ausência de obra" (1964), quando se pergunta

Mais qu'est-ce donc que la philosophie aujourd'hui - je veux dire l'activité philosophique - si elle n'est pas le travail critique de la pensée sur elle-même? Et si elle ne consiste pas, au lieu de légitimer ce qu'on sait déjà, à entreprendre de savoir comment et jusqu'où il serait possible de penser autrement? Il y a toujours quelque chose de dérisoire dans le discours philosophique lorsqu'il veut, de l'extérieur, faire la loi aux autres, leur dire où est leur vérité, et comment la trouver, ou lorsqu'il se fait fort d'instruire leur procès en positivité naïve; mais c'est son droit d'explorer ce qui, dans sa propre pensée, peut être changé par l'exercice qu'il fait d'un savoir qui lui est étranger. L' "essai» - qu'il faut entendre comme épreuve modificatrice de soi-même dans le jeu de la vérité et non comme appropriation simplificatrice d'autrui à des fins de communication - est le corps vivant de la philosophie, si du moins celle-ci est encore maintenant ce qu'elle était autrefois, c'est-à-dire une «ascèse», un exercice de soi, dans la pensée. ${ }^{8}$
6. AGAMBEN, Giorgio. $A$ linguagem e a morte: um seminário sobre o lugar da negatividade, 2006, p. 74 .

7. BATAILLE, Georges. Choix de lettres (1917-1962), 1997, p. 573.

8. FOUCAULT, Michel.

Histoire de la sexualité vol I: La Volonté de savoir, 1976, p. 14-5. 
9. AGAMBEN, Giorgio.

"Archeologia di un'archeologia", 2004, p. XXVI.

\section{Ensaio e arqueologia}

Mas voltemos a Agamben. Em outra ocasião, analisando o conceito de arqueologia que o filósofo Enzo Melandri usara em La linea e il circolo. Studio logico-filosofico sull'analogia (1968), sente-se na obrigação de retomar a diferença entre semântico e semiótico, formulada na mesma época por Émile Benveniste e, portanto, traçar a diferença entre o conceito de arqueologia de Melandri e o de Foucault. A origem do problema residiria, segundo Agamben, no quiasmo ontológico que se produz entre essas duas dimensões. Em 1969, Émile Benveniste apontara, de fato, a fratura entre o semântico e o semiótico, argumentando que o semiótico designa o signo linguístico que o constitui como unidade, em sua identidade consigo mesmo, ao passo que o semântico apontaria ao modo específico da significação gerado pelo discurso. Assim, para Agamben, a distinção benvenistiana entre semiótico e semântico se superpõe, estritamente, à oposição entre semântica nominal e semântica proposicional de Melandri, e essa oposição, por sua vez, torna-se então extrema, já que o modo do signo é fechado, porque não há transição do signo à frase: um hiato enfrenta-os irreconciliavelmente, ao que Agamben então conclui:

Si comprende perché Melandri veda in questa frattura della significazione linguistica uno dei luoghi privilegiati dell'archeologia. Anche se né il filosofo né il linguista si chiedono perché il linguaggio umano comporti questa scissione costitutiva, è certo che soltanto una ricerca archeologica [...] potrebbe risalire a ciò che ha prodotto la scissione, all'evento di cui la scissione è la traccia.

Alla fine del saggio sulla Semiologia della lingua, Benveniste accenna a un possibile superamento della linguistica saussuriana che consiste nella 'analisi translinguistica dei testi e delle opere, attraverso l'elaborazione di una metasemantica che si costruirà sulla semantica dell'enunciazione'. Nella Archeologia del sapere, Foucault riprende questa indicazione scegliendo gli enunciati come oggetto dell'archeologia. L'enunciato non coincide né col semiotico (nei termini di Melandri, con la semantica nominale), né col semantico (con la semantica proposizionale), ma si situa, per cosí dire, sul bordo del discorso, indipendentemente dal gioco del significante e del significato. L'archeologia foucaultiana rivendica come suo territorio non un livello definito dell' analisi linguistica (i nomi, la frase, la proposizione, gli atti illocutivi), ma il puro aver luogo dei discorsi, interroga il senso del loro darsi (in questo senso, essa realizza il programma benvenistiano di una metasemantica fondata sulla teoria dell'enunciazione). ${ }^{9}$

Diríamos, assim, que essa indecibilidade em que a pura 
existência do discurso toma o próprio discurso em seu ato de entrega e circulação entre os leitores é o que define o saggio, isto é, o ensaio, essa forma de cura sui.

\section{Extremos do ensaio}

Vicente Fatone, um dos filósofos latino-americanos que cultivou tanto uma forma sábia quanto uma forma contingente de reflexão acerca dos problemas vitais ${ }^{10}$, definia o pensamento como um modo de ir aos extremos. Tanto no Oriente quanto no Ocidente, argumentava, é indispensável irmos até os elementos mais recônditos que constituem um fenômeno e desenvolvê-los até as suas últimas consequências ${ }^{11}$. Por isso dizia Fatone que toda filosofia é extremista porque, sendo ou não sendo sistemática, quer sempre uma única chave para resolver os problemas, e, nesse sentido, conceitos tais como noûs, ratio, idea ou tao são tão somente índices da indispensável invariante, a partir da qual se constroem finalmente as variações, daí o descrédito em que, costumeiramente, caem as filosofias ecléticas. Nesse sentido, Fatone elenca ainda uma ampla tábula rasa graças à qual conclui que

Extremistas en todos esos sentidos fueron los griegos, a pesar de su "nada en demasía"; extremista fue la filosofía cristiana, aun en su resignada condición de ancilla, por su enderezamiento hacia la "única cosa necesaria"; extremista fue la filosofía del Renacimiento, con el "O César o nada” que a la verdad imponía Galileo; extremista fue la filosofía moderna que partiendo de la clave del ergo cartesiano ofrecería con Leibniz el mejor mundo posible o mostraría la imposibilidad de cualquier otro en la proposición XXXIII de la Ethica de Espinoza. Y extremista es la filosofía contemporánea con su imperativo, con su Ich, con su "todo lo real es racional y todo lo racional es real"; con el salto mortale de Jacobi, con la paradoja de Kierkegaard, con el santo Sí de Nietzsche. ${ }^{12}$

Mas o pensamento oriental, acrescenta Fatone, é igualmente extremista pois, no caso do budismo, parte da contingência ou origem condicionada para concluir que toda aparência de realidade não é senão ilusória e vazia, até mesmo a do nirvana. Prevendo a exigência ascética que Foucault faria no prefácio de $A$ vontade de saber, mas muito antes, em 1932, Fatone já explicava, num ensaio pioneiro sobre o misticismo sufi, aquilo que, na mesma época, estava sendo explorado por Bataille com seu conceito de experiência interior.
10. A primeira pode ser resgatada em seus livros Misticismo épico ou O budismo niilista; a segunda, porém, nos 181 pequenos ensaios, publicados entre 1939 e 1947, no jornal El Mundo, dando, de certa forma, complemento e continuidade às águas-fortes portenhas de Arlt, estampadas pelo mesmo jornal, só que com um enfoque mais zombeteiro e erudito, oriental, sem nunca ser pedante entretanto.

11. Como mostra Remo Bodei, isto se explica por um mútuo cruzamento. "La filosofía de la Grecia arcaica tiene raíces asiáticas y egipcias, y la del período clásico llega al Occidente medieval a través de un largo derrotero [...]; Leibniz comienza a insertar el pensamiento chino en la gran familia del pensamiento humano; Schopenhauer hace ingresar a pleno título en la cultura europea al budismo [... y el hinduismo, o sea el núcleo principal de la tradición hindú [...]. Otra migración de pensamientos se constituye luego, para ampliar el radio geográfico hasta el Extremo Oriente, con la llegada de la filosofía europea al Japón en la segunda mitad del siglo XVI. En el país del sol naciente, los conocimientos aportados por los occidentales fueron definidos inicialmente como nanbangaku (ciencia de los bárbaros del sur), mientras que en el siguiente período (el Edo, que va desde el 1600 al 1867), fueron llamados en cambio rangaku (ciencias holandesas). A diferencia de los misioneros jesuitas españoles y portugueses - quienes, de todos modos, hicieron conocer la existencia de las obras de Aristóteles, san Agustín y santo Tomás -, los holandeses eran bien recibidos en Japón, ya que carecían de propósitos hegemónicos y no les interesaba 
la evangelización [...]. En la búsqueda de un término para traducir la palabra 'filosofía', los japoneses lo encontraron, en primera instancia, en gakushi (conocimiento general, sabiduría, enseñanza) y, más adelante, en tetsugaku (ciencia y sabiduría)". BODEI, Remo. La chispa y el fuego. Invitación a la filosofía, 2006, p. 55-56.

12. FATONE, Vicente.

"Extremismo de la filosofía oriental". Cursos y Conferencias, 1948.

13. Idem. "El misticismo sufí". Nosotros, 1932.

14. Idem. "Definición de la mística". Ínsula, 1943, mais tarde incorporado a Temas de místicay religión. Cf. Mistica y religión, 2009, p. 35-44. Retomei a tipologia de Fatone em meu ensaio "Poesia e modernismo: pré-lógica, formal, dialética e pós-lógica". Revista do Instituto de Estudos Brasileiros, 2012, p. 43-57.

15. A bibliografia sobre o ensaio é muito vasta. Além do clássico "O ensaio como forma" de Adorno, caberia lembrar de LUKÁCS, Georg. "Sobre la esencia y la forma del ensayo", 1985, p. 15-39; GENETTE, Gérard. "Introduction à l'architexte", 1986, p. 89-159. Destaco, no domínio latinoamericano: CLEMENTE, José Edmundo. El ensayo, 1961; GRÜNER, Eduardo. "El ensayo, un género culpable". Sitio, 1985, p. 51-56, mais tarde incluído em Un género culpable (2014); REAL DE AZÚA, Carlos. "¿Un género ilimitado?" e "Un género limitable", 1964, p. 11-30; RITVO, Juan Bautista. "El ensayo de interrupción". Boletín del Centro de estudios de teoría y crítica literaria, 2002; GIORDANO, Alberto. Modos del ensayo. Jorge Luis Borges, Oscar Masotta, 1991; SANTÍ, Enrico Mario. "Introducción”, 2000,
La unión con Dios (la unión en el éxtasis o la unión después de la muerte) importa simplemente la comunión de las voluntades humana y divina, y nunca la confusión de las personas. En el momento del itinerario sufí (veneración, amor, concentración, imaginación, éxtasis, aniquilación, comunión, recuperación del yo) desaparece hasta la conciencia de haber alcanzado la meta. Es el momento en que se trasciende la misma trascendencia: noche oscura del alma, noche absoluta semejante a la absoluta noche del cuerpo entregado al embalsamador; pero inmediatamente el sufí entra en la comunión auténtica donde la personalidad conserva su naturaleza. ${ }^{13}$

Mais tarde, em "Definición de la mística", um ensaio de 1943, Fatone definirá quatro momentos da experiência absoluta, que são o momento pré-lógico, o momento formal, o momento dialético e o momento místico ${ }^{14}$. Desenham-se aí, se bem se analisa, duas das linhas mais importantes que percorreria o ensaio latino-americano a partir dos anos 30. De um lado, um extremismo ontológico da nação que, admitindo a existência de uma tradição dita ocidental, propunha a metafísica do ser específico como estratégia de apropriação de um limite dilacerado ou simples entre-lugar que guardaria a memória da marca originária. Buscava-se assim a reapropriação do melhor dessa cultura, como arma contra o pior dela mesma, situação ambivalente, em que, de maneira tímida e tateante, o Ocidente se contemplaria a si próprio como Outro de si mesmo. Essa posição que, simplificando, poderíamos chamá-la de tupy or not tupy, perpassou um conjunto de ensaios de interpretação nacional (ou de fragmentos da nação, como a raça e o gênero) redigidos em plena crise da relação colonial constitutiva, acelerada aliás pela crise do próprio capitalismo em 1930: Retrato do Brasil de Paulo Prado; Raízes do Brasil de Sérgio Buarque de Holanda; Casa grande e senzala, Sobrados e Mocambos e Nordeste de Gilberto Freyre; Confissões de Minas de Carlos Drummond de Andrade; Radiografía de la pampa e La cabeza de Goliat de Ezequiel Martínez Estrada; Seis ensayos en busca de nuestra expresión de Pedro Henríquez Ureña; El nacionalismo continental de Joaquín Edwards Bello; Siete ensayos de interpretación de la realidad peruana de José Carlos Mariátegui; Tratado de Metafísica, Bolivarismo y monroísmo e De Robinsón a Odiseo de José Vasconcelos; La sensibilidad americana de Emilio Frugoni; Proceso intelectual del Uruguay de Alberto Zum Felde; La formación de una filosofía propia o sea latinoamericana de Francisco Gavidia; El hombre que está solo y espera de Raúl Scalabrini Ortiz; Teoría del Nous de Emilio Oribe; Insularismo: ensayos de interpretación puertorriqueña de Antonio S. Pedreira; De cómo se ha formado la nación colombiana de Luis López de Mesa; El arte y las masas de Elías Castelnuovo; Vida y pasión de la cultura en América de 
Luis Alberto Sánchez; ¿Adónde va Indoamérica? de Víctor Raúl Haya de la Torre; Educación y lucha de clases de Aníbal Ponce; La mujer y su expresión de Victoria Ocampo; El hombre prisionero de Héctor P. Agosti; Descenso y ascenso del alma por la belleza de Leopoldo Marechal; Contribución a la realidad de Benjamín Subercaseaux; Contrapunteo cubano del tabaco y el azúcar de Fernando Ortiz; Formación y proceso de la literatura venezolana e De la conquista a la independencia. Tres siglos de historia cultural hispanoamericana de Mariano Picón Salas; Biografía del Caribe de Germán Arciniegas; Uno y el universo de Ernesto Sabato; Nueva grandeza mexicana de Salvador Novo; La música en Cuba de Alejo Carpentier; La poesía quechua de Jesús Lara; Interpretación dialéctica de América. Los cinco estilos del Pacífico: Chile, Perú, Bolivia, Ecuador, Colombia de Pablo de Rokha; Muerte y transfiguración de Martín Fierro: ensayo de interpretación de la vida argentina de Ezequiel Martínez Estrada; El mito gaucho. Martín Fierro y el hombre argentino de Carlos Astrada; Pequeña sinfonía del Nuevo Mundo de Luis Cardoza y Aragón; Meditaciones sobre México de Jesús Silva Herzog; Discours sur le colonialisme de Aimé Césaire e Lima la horrible de Salazar Bondy, até chegarmos ao ensaio que, certamente, encerra a série, $O$ labirinto da solidão de Octavio Paz, tão tardio quanto $O$ escritor argentino e a tradição ocidental de Borges, lido em forma de palestra em 1947 mas só publicado na revista Sur em $1955^{15}$.

\section{Trangressão contra melancolia}

De outro lado, porém, teríamos algumas experiências que, como apontava Fatone, em vez de destacarem o ser, enfatizam o nada e, nesse sentido, buscam uma epistemologia negativa, de que o melhor exemplo são, sem dúvida, os ensaios de Lezama Lima ${ }^{16}$. Esta epistemologia negativa seria uma forma de resgate ou reconciliação com o mais arcaico da experiência ascética. Aliás, já nos anos 50, Eugeni D'Ors separava, a tal efeito (valendo-se da metáfora flamenca, por soledades, por seguidillas $^{17}$ ), o que ele chamava pensar por ensaios, que vinculava, em um mesmo abraço, barrocos e contemporâneos, do pensar por saberes, que era o tipo de experiência positiva do século XIX ${ }^{18}$.

Ora, quatro anos separam $O$ labirinto da solidão e $O$ pecado original da América Latina. O livro de Octavio Paz é de 1950, ao passo que o ensaio de Héctor A. Murena saiu em 1954. Mas se o primeiro encerra a fase ontológica diferencial, de tupy or not tupy, o segundo abriria a do pós-ensaio p. 13-132; RODRIGUEZ

PERSICO, Adriana. Relatos de época: una cartografía de América Latina (1880-1920), 2008;

QUINTERO HERENCIA,

Juan Carlos. Fulguración del espacio.

Letras e imaginario institucional de

la Revolución cubana (1960-1971), 2002; FERRER, Christian.

"Melodías, sonetos, papers". Babel, 1990; GONZÁLEZ, Horacio. Restos pampeanos, ciencia, ensayo y política en la cultura argentina del siglo XX, 1999; Idem. "Cien años de sociología en la Argentina: la leyenda de un nombre", 2000, p. 15-100; Idem. "Ensayo y memorándum".

Boletín del Centro de estudios de teoría y crítica literaria, 2002; MATTONI, Silvio. Las formas del ensayo en la Argentina de los años '50, 2003; PANESI, Jorge. "Cultura, crítica y pedagogía en la Argentina: Sur / Contorno", 2002, p. 49-64; MAÍZ, Claudio. El ensayo: entre género y discurso, 2004; CUETO, Sergio e GIORDANO, Alberto. Borges y Bioy Casares ensayistas, 1988.

16. Cf., a esse respeito, COLLAZOS, Óscar. "La expresión americana”, 1987, p. 379-387; CHIAMPI, Irlemar. "La historia tejida por la imagen”, 1993, p. 9-33.

17. DIDI-HUBERMAN, Georges. El bailaor de soledades, 2008.

18. D ORS, Eugeni. "Pensar por ensayos (I. Los Moralistas; II. Séneca. Vives. Jiménez de Cisneros; III. Gracián; IV. Clavijo. Larra. Donoso. Balmes; V. Los contemporáneos)". Clavileño. Revista de la Asociación Internacional de Hispanismo, 1953, p. 1-6; Idem. "Pensar por saberes (I. La crítica y la Historia; II. Menéndez y Pelayo; III. Otros saberes; IV. La Teología. Prisciliano; V. Lulio; VI. Molinos; VII. Ignacio; VIII. La mística. Los modernos)". Clavileño. Revista de la Asociación Internacional de Hispanismo, 1953, p. 1-5. 
19. MURENA, Héctor.

"Ser y no ser de la cultura latinoamericana". Cuadernos, 1961, p. 143-152. O texto seria incorporado, a seguir, a Ensayos sobre subversión.

\section{BATAILLE, Georges;} LEIRIS, Michel. Intercambios y correspondencias 1924-1982, 2008, p. 133.

21. MURENA, Héctor. Ensayos sobre subversión, 1962. Cf., na mesma linha, LIBERTELLA, Héctor. "La librería argentina", 1993, p. 201-242.

22. Idem. "La epifanía de lo desconocido". La Nación, 1961.

23. SHESHADRI, Kalpana. "Agamben, the Thought of Steresis: An Introduction to Two Essays". Critical Inquiry, 2014.

24. No original: tou auton kai kata to auto pasa dynamis adynamia. $\mathrm{Na}$ tradução de Jules Tricot (Paris, Vrin, 1953): "la science est la raison des choses, et que c'est la même raison qui explique l'objet et la privation de l'objet, bien que ce ne soit pas de la même manière : en un sens, c'est à la fois l'objet et sa privation, mais, en un autre sens, c'est plutôt l'objet positif". que analisa, em condição de igualdade, tanto o ser quanto o não-ser da cultura latino-americana ${ }^{19}$. A esse respeito, caberia relembrar que, numa carta a Bataille, Michel Leiris dizia que, em Blanchot, existia uma forma de transcendência, essa basculação sim-não, que era muito próxima, por sinal, do conceito de experiência interior do destinatário ${ }^{20}$. Da mesma forma, Murena reivindica, com efeito, no prefácio a Ensayos sobre subversión, o caráter anacrônico da escrita ensaística ${ }^{21}$, muito embora em um artigo prévio para La Nación, em 1961, "La epifanía de lo desconocido”, ele mesmo já dissesse que, tanto as filosofias da crise, quanto as da imersão no instante, que são ambas sintomas do contemporâneo, corroboravam sermos apenas testemunhas de uma época de "epifanía del futuro en bruto”22, ou seja, que, como já apontou, aliás, Sílvio Mattoni, o anacronismo reivindicado por Murena se voltaria à potência da escrita nietzscheana, como pensamento inatual e mesmo fragmentário, que subverte a atualidade das verdades positivas extrapoladas de sua história, porém eternizadas em função de um outro tempo instalado no cerne mesmo do presente.

Sabemos que a teoria do pensamento de Agamben, tal como expressa no ensaio sobre Bartleby ou no Homo sacer, repousa no conceito de stéresis (privação, recuo ou desativação) e que este, por sua vez, mantém uma correlação com o de dynamis ou de potência ${ }^{23}$. Previamente Heidegger chamara a atenção para o fragmento 1046a, 32 da Metafísica de Aristóteles, onde se afirma que, em relação e de acordo com algo dado, cada força ativa é também força passiva ${ }^{24}$. Murena desenvolveria essa mesma teoria da stéresis da escrita em vários ensaios, deles destacando-se $A$ metáfora e o sagrado (1973). Na basculação entre ser e não-ser latino-americano (que é uma forma de afirmar ser e não-ser contemporâneo), Murena reconstrói a melancolia da modernidade (a filosofia da crise) e, em compensação, argumenta que

Para la mística, no puede ocurrir de otro modo: aunque acontezca que una criatura carezca de todo, en la medida en que tenga a Dios no sentirá que le falta nada. Porque lo cierto es que el melancólico experimenta la nostalgia de lo que le falta a causa de que "antes" ha mirado al pasado o al futuro, al tiempo como tiempo en sí, esencia de las privaciones y la caída. El hombre de fe necesita vivir, consumar todas sus energías, en el presente, en el instante indivisible, incesante e inaprehensible - cuya entrada no se abre con la voluntad o la razón o la pasión, sino con la totalidad del ser -, pues por constituir éste el punto en que la eternidad se refleja en el tiempo es el conductor por el que Dios entra en el hombre y la puerta por la que en cada instante puede llegar o volver el Mesías. Todo llama al hombre de fe para que se concentre en el presente: a este hombre esencialmente fuera del tiempo le falta tiempo - 
sentido de la temporalidad - para considerar ese pasado y ese futuro que engendran la melancolía. Para este hombre cuya vida es el arte de dejarse traspasar por el Otro Mundo no sólo carece de sentido sino que es además prueba de infidelidad ese arte nacido de la melancolía que se limita a tratar de mostrar el Otro Mundo. Para el derviche que alcanza el éxtasis mediante el arte de la danza esa danza no tiene sentido en el momento de su éxtasis, pues únicamente la alcanza a fuerza de repetir de modo uniforme el mismo movimiento: cuando la danza se anula a sí misma y desaparece. ${ }^{25}$

Não era esse o discurso emergente em 1973. O místico Murena ${ }^{26}$ estava bem distante das posições politicamente vanguardistas daquela hora, tanto quanto Bataille, face a Breton, sentia-se repetindo a relação São João da Cruz-Santa Teresa ${ }^{27}$. Com efeito, na primavera de 1972, um número dedicado à "crítica política da cultura" da revista que talvez melhor ilustre o telquelismo latino-americano ${ }^{28}$, Los libros, divulgava as respostas que um conjunto de críticos dera a um questionário (previsivelmente elaborado por Beatriz Sarlo e Carlos Altamirano $^{29}$ ). É um bom mostruário da filosofia da crise e da melancolia de esquerda. Josefina Ludmer dizia, por exemplo, que os escritores produzem espelhos onde se tautologizam, com regozijo, não só o artista burguês mas também seus leitores, impondo a negação absoluta de qualquer efeito de leitura, através da suspensão e mesmo da oclusão da rede expansiva da significação. O sistema decreta e congela, ponderava Ludmer, os grupos cúmplices escolhem a cegueira e o romance de supermercado, a literatura de plástico para o fim de semana, o exotismo, o relato ornamentado e divertido, o livro para presentear, o gadget literário, o romance como troféu de viagem, como souvenir, a meritocracia literária, a ética do jogo e do tempo livre, a pseudorrevolução ${ }^{30}$. Ricardo Piglia, por sua vez, concluía sua intervenção argumentando em favor de um trabalho crítico organicamente ligado à luta política das massas, o que implicava confrontar-se com uma tradição muito enraizada na crítica de esquerda latino-americana, acostumada a ver os textos não como um sintoma ou um tecido de relações, mas como o efeito de uma decisão livre e soberana, em que o crítico e o escritor disputavam, em particular, a razão e o lugar do sentido $^{31}$. Simultaneamente, e numa atitude completamente antagônica, Murena reatava o vínculo com uma tradição hermética e mallarmeana, que o levaria a pensar escritura e silêncio.

El universo es un libro, dice la sabiduría: todo libro encierra el universo. Hay que recordar, sin embargo, que el trazo negro de cada palabra se torna inteligible en el libro merced a lo blanco de la página. Ese blanco del que la palabra brota y en el que acaba por desaparecer es el Silencio
25. MURENA, Héctor. La metáfora y lo sagrado, 2012, p. 42-43.

26. Em 1973, Jean-Louis Baudry publicava na Tel quel seu ensaio sobre Bataille e a experiência interior. Cf. BAUDRY, Jean Louis. "Bataille and Science: Introduction to Inner Experience", 1995, p. 265-281.

27. É o que o mesmo Bataille diz a André Masson numa carta de 1942. Cf. BATAILLE, Georges. Choix de lettres (19171962), 1997, p. 180.

28. WOLFF, Jorge. Telquelismos latinoamericanos: la teoría crítica francesa en el entre-lugar de los trópicos, 2009.

29. Sarlo, de fato, assinava, no mesmo número, o ensaio a seguir: "La enseñanza de la literatura: Historia de una castración". A esse respeito, Cf. MANGONE, Carlos; WARLEY, Jorge. "La modernización de la crítica”, 1980- 1986.

30. LUDMER, Josefina.

"Resposta à enquete 'Hacia la crítica". Los libros, 1972.

31. PIGLIA, Ricardo.

"Resposta à enquete 'Hacia la crítica"'. Los libros, 1972. Para desenvolvimentos posteriores destes mesmos autores, Cf. PIGLIA, Ricardo. Crítica y ficción, 2001 e SARLO, Beatriz. "La perspectiva americana en los primeros años de Sur". Punto de Vista, 1983; Idem. "Los dos ojos de Contorno". Revista ibero-americana, 1983; Idem. "La crítica: entre la literatura y el público". Espacio de crítica y producción 1984; Idem. "El ensayo como forma del problema argentino. Una aproximación a Radiografía de la pampa". Dispositio ,1984. 
32. MURENA, Héctor. La metáfora y lo sagrado, 2012, p. 62-64.

33. Ibidem, p. 93. primordial. Principio y fin de cada criatura, de todo lo creado, el blanco escribe para nosotros lo fundamental de toda escritura: el círculo de misterio que envuelve nuestra existencia. La calidad de cualquier escritura depende de la medida en que transmite el misterio, ese silencio que no es ella. Su esplendor es enriquecedora abdicación de sí. Y ésta resulta evidente en el tipo de lectura que permite y exige. La palabra portadora de misterio demanda una lectura lenta, que se interrumpe para meditar, tratar de absorber lo inconmensurable: pide relectura, consideración del blanco. Arquetipo son las escrituras de las religiones, que invocan el fin de sí mismas, la restitución del secreto fundamental. Arquetipo, también, las grandes obras de la literatura, aquellas cuya esencia es poética, pues la metáfora, con su multivocidad, pluralidad de sentidos, dice que está procurando decir lo indecible: el silencio. Frente a éstas se alzan los textos utilitarios, que pueden leerse con rapidez y que, si por un lado nos fuerzan a salir de nosotros mediante la diversión o la información, por otro nos empobrecen radicalmente al negar el blanco, el silencio, el misterio. A lo largo de siglos la literatura se vio corrompida de modo cada vez más profundo por ese espíritu utilitario. La novela sin poesía oscureció a la poesía. El espejismo aritmético llamado sociología remplazó al reverente vacilar, escuela de vacilación, llamado filosofía. Hoy tocamos límites. La babelización de la escritura indica aguda nostalgia mala del silencio que la gran obra por naturaleza encierra y busca. La catástrofe de la letra escrita testimonia en forma invertida que la literatura surge de la necesidad de Dios. ${ }^{32}$

E, mais adiante, completando:

El hombre de Babel buscaba restañar la Falta originaria en el erróneo modo que lo conduciría a repetir la Falta originaria. Pero ese intento, aunque hubiera llegado a consumarse, es de naturaleza distinta al que subyace en el episodio de la serpiente. Al comer el fruto el hombre quería hacerse "como Dios". Bajo la trasgresión de la Torre se hallaba la inocencia de querer volver, de desmentir y borrar la concupiscencia inicial. Con su acción Yahveh reconoce en forma tácita esa raíz de pureza: no aniquila al hombre, no vuelve a degradarlo como ente, no lo expulsa a reinos más adversos que la Tierra. Lo reencamina: tras la ironía ("ahora ya no les será difícil cuanto proyecten hacer”, ironía que es un eco de la ironía de que junto al saber total exista el Árbol de la Ciencia), está la caridad de Yahveh. La dispersión por la Tierra, la confusión de la lengua tienen por fin indicar otra vez al hombre cuál es su naturaleza, cuál es su destino: la diversidad, el reino de las diferencias. El gesto de Yahveh libera al hombre de la locura del discurso único, de la obsesión del regreso: le indica que el camino de retorno está para él sólo a través de la aceptación de la diversidad. ${ }^{33}$ 
Héctor A. Murena, o primeiro tradutor de Benjamin ao espanhol (e lembremos que, em sua resposta a Los libros, Piglia confessava estar trabalhando sobre o conceito de tradução como modo de apropriação e gênese do valor, o que aliás ilustraria, em 1974, seu próprio relato Nome falso) demandava, com seu ensaio, a dimensão do neutro, já não no domínio em que, tradicionalmente, o buscara a ontologia do ser nacional, isto é, no campo da racionalidade e do pensamento, mas, efetivamente, e à maneira de Blanchot, na esfera da escritura. Coincidia assim esse seu ensaio pós-lógico e babelicamente pós-literário, com a translatio global de Emily Apter ${ }^{34}$ e mesmo com o diagnóstico formulado por Roberto Esposito, no sentido de um ensaio in-operante:

Prima ancora, e forse meglio, del pensiero, a incontrare il neutro è stata la scrittura - quella forma di espressione che, al contrario della parola parlata, trova il proprio senso ultimo non tanto nel 'fare opera', ma piuttosto nel disattivarla, o 'disoperarla', esponendola alla sua irrimediabile perdita di padronanza. Non a caso fin da sempre, «scrivere equivale a passare dalla prima alla terza persona», vale a dire all'«evento non illuminato di ciò che avviene quando si racconta»

[Trata-se, é bom esclarecer, de duas citações de $A$ conversa infinita de Blanchot].

Se in una prima fase - quella della forma epica - la terza persona costituiva «la coerenza impersonale di una storia», successivamente, a partire da Cervantes, è diventata «il quotidiano senza impresa, ciò che accade quando non accade nulla». Essa segna la rinuncia dello scrittore alla possibilità di dire 'io' a favore dei personaggi, destinati così a incarnare una terza persona multipla coincidente con le vite individuali di cui essi sono portatori. Finché, a un certo punto, alla fine della stagione moderna, nel cuore dell'impersonalità si determina un ulteriore sdoppiamento tra il ritiro del romanziere dietro le quinte, rappresentato in maniera esemplare da Flaubert, e il ben più devastante decentramento operato da Kafka. Con lui l'assenza della voce narrativa penetra, come un'irriducibile estraneità, non solo nella soggettività dei personaggi, ma nella struttura stessa dell'opera. È questo passaggio, precisamente, che inaugura il regno del neutro nella modalità peculiare della terza persona. ${ }^{35}$

Nesse ponto extremo, o ensaio latino-americano encontra, enfim, a possibilidade de escrever a experiência sem limites, o que de resto comprova aquilo que Hannah Arendt dizia na epígrafe inicial, que o ensaio, como forma literária, é um exercício de experiência íntima, ao que a teórica alemã acrescentava: o ensaio não tem a unidade de um conjunto mas se apresenta como uma sequência de movimentos que, como uma suíte musical, são escritos na mesma ou semelhante chave ("a se-
34. APTER, Emily. The translation zone: A new comparative literature, 2006.

35. ESPOSITO, Roberto. Terza persona. Politica della vita e filosofia dell'impersonale, 2007, p. 159-160. 
36. ARENDT, Hannah. Between Past and Future. Eight exercises in political thought, 1961, p. 15. quence of movements which, as in a musical suite, are written in the same or related keys" ${ }^{36}$ ). Arendt, ocidental, pensava na suíte barroca, que é uma colcha de retalhos étnicos concebida para dançar comunitariamente. Murena, em viagem oriental, pensou, no entanto, o ensaio como uma dança derviche, como um teste, ou como diria Foucault, "une épreuve modificatrice de soi-même dans le jeu de la vérité”, concebida para escrever a impossível relação entre a metáfora (o círculo) e o sagrado (a linha), ou seja, para confirmar a sutil comunidade dos que carecem de algo em comum. 


\section{Referências}

AGAMBEN, Giorgio. A linguagem e a morte: um seminário sobre o lugar da negatividade. Trad. Henrique Burigo. Belo Horizonte: Editora UFMG, 2006.

"Archeologia di un'archeologia”. In: MELANDRI, Enzo. La linea e il circolo. Macerata: Quoblibet, 2004, p. xixxxv.

. La potenza del pensiero. Saggi e conferenze. Vicenza:

Neri Pozza, 2001.

ANTELO, Raul. "Poesia e modernismo: pré-lógica, formal, dialética e pós-lógica”. Revista do Instituto de Estudos Brasileiros, $\mathrm{n}^{\mathrm{a}}$ 55, p.43-57, mar./set. 2012.

APTER, Emily. The translation zone: A new comparative literature. Princeton: Princeton University Press, 2006.

ARENDT, Hannah. Between Past and Future: Eight exercises in political thought. New York: The Viking Press, 1961.

BAILEY GILL, Carolyn. Bataille: writing the sacred. London: Routledge, 1995.

BATAILLE, Georges. Choix de lettres (1917-1962). Paris : Gallimard, 1997.

L'apprenti sorcier. Textes, lettres et documents (1932-9). Ed. Marina Galetti. Paris : Ed. de la Différence, 1999.

BATAILLE, Georges; LEIRIS, Michel. Intercambios y correspondencias 1924-1982. Ed. Louis Yvert. Trad. Silvio Mattoni. Buenos Aires: Cuenco de plata, 2008.

BAUDRY, Jean Louis. "Bataille and Science: Introduction to Inner Experience”. In: BOLDT-IRONS, Leslie Anne (ed.). On Bataille. Critical Essays. Albany: State University of New York, 1995, p. 265-281.

BODEI, Remo. La chispa y el fuego: Invitación a la filosofía. Trad. Heber Cardoso. Buenos Aires: Nueva Visión, 2006.

CASTRO, Edgardo. Giorgio Agamben: una arqueología de la potencia. Buenos Aires: Jorge Baudino Ediciones / UNSAM EDITA, 2008.

CHIAMPI, Irlemar. "La historia tejida por la imagen”. In: LEZAMA LIMA, José. La expresión americana. México: Fondo de Cultura Económica, 1993, p. 9-33. 
CLEMENTE, José Edmundo. El ensayo. Buenos Aires: Ediciones Culturales Argentinas, 1961.

COLLAZOS, Óscar. "La expresión americana”. In: SUÁREZGALBÁN, Eugenio (ed.). Lezama Lima, El escritor y la crítica. Madrid: Taurus, 1987, p. 379-387.

CUETO, Sergio e GIORDANO, Alberto. Borges y Bioy Casares ensayistas. Rosario: Paradoxa, 1988.

DIDI-HUBERMAN, Georges. El bailaor de soledades. Valencia: Pre-textos, 2008.

D 'ORS, Eugeni. "Pensar por ensayos (I. Los Moralistas; II. Séneca. Vives. Jiménez de Cisneros; III. Gracián; IV. Clavijo. Larra. Donoso. Balmes; V. Los contemporáneos)”. Clavileño. Revista de la Asociación Internacional de Hispanismo. a. IV, n⿳⺈ 19, p.1-6, jan./fev. 1953.

- "Pensar por saberes (I. La crítica y la Historia; II. Menéndez y Pelayo; III. Otros saberes; IV. La Teología. Prisciliano; V. Lulio; VI. Molinos; VII. Ignacio; VIII. La mística. Los modernos)". Clavileño. Revista de la Asociación Internacional de Hispanismo. a. IV, $\mathrm{n}^{-\mathrm{a}}$ 21, p. 1-5 mai./jun. 1953.

ESPOSITO, Roberto. Terza persona. Politica della vita e filosofia dell'impersonale. Torino: Einaudi, 2007.

FATONE, Vicente. "Definición de la mística”. Ínsula. n. 3, p. 192-199, 1943.

1932.

."El misticismo sufi”. Nosotros. n. 272, p. 46-53,

. "Extremismo de la filosofía oriental". Cursos y Conferencias. v. XVII, n ${ }^{-1}$ 197-98, p. 298-306, 1948.

. Mística y religión. Pref. Oscar del Barco. Buenos Aires: Las Cuarenta / Córdoba: UNC, 2009.

FAYE, Jean-Pierre. "Feu et froid: le Collège de Sociologie autour de Georges Bataille”. In: LECOQ, Dominique; LORY, Jean-Luc (ed). Écrits d'ailleurs. Georges Bataille et les ethnologues. Paris : Maison des Sciences de 1'Homme, 1987.

FERRER, Christian. "Melodías, sonetos, papers". Babel. a. 3, $\mathrm{n}^{\mathrm{a}}$ 18, p. 22-23, ago. 1990.

FOUCAULT, Michel. Histoire de la sexualité. Vol I: La Volonté de savoir. Paris : Gallimard, 1976.

GENETTE, Gérard. "Introduction à l'architexte”. In: Théorie des genres. Paris: Seuil, 1986, p. 89-159. 
GIORDANO, Alberto. Modos del ensayo. Jorge Luis Borges, Oscar Masotta. Rosario: Beatriz Viterbo, 1991.

GONZÁLEZ, Horacio. "Cien años de sociología en la Argentina: la leyenda de un nombre”. In: VÁRIOS. Historia crítica de la sociología argentina. Buenos Aires: Colihue, 2000, p. 15-100.

“Ensayo y memorándum”. Boletín del Centro de estudios de teoría y crítica literaria. n⿳a 10, p. 9-23, dez. 2002. - Restos pampeanos, ciencia, ensayo y política en la cultura argentina del siglo XX. Buenos Aires: Colihue, 1999. GRASSI, Carlo. Il non-sapere. Georges Bataille, sociologo della conoscenza. Pref. Marc Augé. Milano: Costa \& Nolan, 1998.

GRÜNER, Eduardo. "El ensayo, un género culpable”. Sitio. $\mathrm{n}^{\mathrm{a}}$ 4-5, p. 51-56, mai. 1985.

LIBERTELLA, Héctor. "La librería argentina”. In: Las sagradas escrituras. Buenos Aires: Sudamericana, 1993, p. 201-242.

LUDMER, Josefina. "Resposta à enquete 'Hacia la crítica”. Los libros. n. 28, p. 6, set. 1972.

LUKÁCS, Georg. "Sobre la esencia y la forma del ensayo”. In: . El alma y las formas: Teoría de la novela. México:

Grijalbo, 1985. p. 15-39.

MAÍZ, Claudio. El ensayo: entre género y discurso. Mendoza: Facultad de Filosofía y Letras, 2004.

MANGONE, Carlos; WARLEY, Jorge. "La modernización de la crítica”. In: Historia de la Literatura Argentina. Vol. 5. Buenos Aires: Centro Editor de América Latina, 1980- 1986.

MATTONI, Silvio. Las formas del ensayo en la Argentina de los años ’50. Córdoba: Universitas, 2003.

MURENA, Héctor. Ensayos sobre subversión. Buenos Aires: Sur, 1962.

1961. . "La epifanía de lo desconocido". La Nación. 21 mai. . La metáfora y lo sagrado. Buenos Aires: El Cuenco de Plata, 2012. . "Ser y no ser de la cultura latinoamericana".

Cuadernos. n ${ }^{-}$53, p. 143-152, out. 1961 
PANESI, Jorge. "Cultura, crítica y pedagogía en la Argentina: Sur / Contorno". In: . Críticas. Buenos Aires: Norma, 2002, p.49-64.

PIGLIA, Ricardo. Crítica y ficción. Barcelona: Anagrama, 2001.

. "Resposta à enquete 'Hacia la crítica”". Los libros. n. 28, p. 7, set. 1972.

QUINTERO HERENCIA, Juan Carlos. Fulguración del espacio. Letras e imaginario institucional de la Revolución cubana (1960-1971). Rosario: Beatriz Viterbo, 2002.

REAL DE AZÚA, Carlos. “¿Un género ilimitado?”; “Un género limitable”. In: Antología del ensayo uruguayo contemporáneo. Montevidéu: Universidad de la República, Departamento de Publicaciones, 1964, p. 11-30.

RITVO, Juan Bautista. "El ensayo de interrupción”. Boletín del Centro de estudios de teoría y crítica literaria. $\mathrm{n}^{\mathrm{a}} 10$, dez. 2002.

RODRÍGUEZ PÉRSICO, Adriana. Relatos de época: una cartografía de América Latina (1880-1920). Rosario, Beatriz Viterbo, 2008.

SANTÍ, Enrico Mario. “Introducción”. In: PAZ, Octavio. El laberinto de la soledad. Madrid: Cátedra, 2000, p. 13-132.

SARLO, Beatriz. "El ensayo como forma del problema argentino. Una aproximación a Radiografía de la pampa”. Dispositio. v. 9, n. 24-26, p. 149-159, 1984.

. "La crítica: entre la literatura y el público". Espacio de crítica y producción. n. 1, dez. 1984.

. "La perspectiva americana en los primeros años de Sur”. Punto de vista. n. 17, p.10-12, 1983.

. "Los dos ojos de Contorno". Revista iberoamericana. n. 125, p.797-807, out/dez. 1983.

SHESHADRI, Kalpana. "Agamben, the Thought of Steresis : An Introduction to Two Essays”. Critical Inquiry. v. 40, n⿳亠丷厂 2, winter 2014.

WOLFF, Jorge. Telquelismos latinoamericanos: la teoría crítica francesa en el entre-lugar de los trópicos. Buenos Aires: Editora Grumo, 2009. 